\title{
Screening of the EMEP source receptor relationships: application to five European countries
}

\author{
A. Clappier ${ }^{1} \cdot$ H. Fagerli $^{2} \cdot$ P. Thunis ${ }^{3}$
}

Received: 10 August 2016/Accepted: 7 October 2016/Published online: 25 October 2016

(C) Springer Science+Business Media Dordrecht 2016

\begin{abstract}
In this work, a methodology based on the calculation of potencies and potentials is used to screen modeled emission reduction scenarios performed with the European Monitoring and Evaluation Programme/Meteorological Synthesizing Centre-West (EMEP/MSC-W) air quality model. Specific indicators are proposed to look at the results in terms of model processes (potencies) as well as in terms of their impacts on policy (potentials). A specific template to screen the results is also developed and applied. The EMEP/MSC-W model results obtained for 5 EU countries for 5 precursors and 2 levels of emission reductions (15 and $40 \%$ ) are analyzed with the following purposes: (i) build confidence in the processes implemented in the model, (ii) identify potential for national abatement versus transboundary transport, (iii) assess the relative importance of various precursor emissions, and (iv) estimate the importance of non-linearity with respect to the level of emission reduction chosen and among the precursor emissions. The proposed methodology proves to be very useful for comparing the responses across countries and precursors in a uniform way. The results confirm our knowledge in terms of processes implemented in the EMEP/MSC-W model. The validity of the linear assumption made during the derivation of the EMEPbased source receptor relationships is generally valid although
\end{abstract}

A. Clappier

clappier@unistra.fr

1 Laboratoire Image Ville Environnement, Université de Strasbourg, Strasbourg, France

2 Norwegian Meteorological Institute, Oslo, Norway

3 European Commission, Joint Research Centre (JRC), Directorate for Energy, Transport and Climate, Air and Climate Unit, Ispra, Italy minor non-linearities with respect to $\mathrm{NH}_{3}$ (all countries) and $\mathrm{NO}_{\mathrm{x}}$ (in Italy) are observed. Because no true reference can be used to assess the quality of the model results in scenario mode, it is important to consider this screening as a benchmark to which other models or updated versions of the EMEP/MSC-W model can be compared to in the future.

Keywords Air quality modeling - Integrated assessment . Source receptor relationships $\cdot$ Non-linearities

\section{Introduction}

Models are increasingly used in Europe for simulating air quality. This is the result, among others, of the 2008 European Directive on Ambient Air Quality and Cleaner Air for Europe (AQD 2008) which encourages modeling as one of the means to perform air quality management tasks (EEA 2011). Indeed, where and whenever EU limit thresholds are exceeded, authorities have a formal obligation to design air quality plans. Models are then very useful to support air quality management and in particular assess the impact of those plans on air quality. The same holds at the European scale where the European Monitoring and Evaluation Programme/Meteorological Synthesizing Centre-West (EMEP/MSC-W) air quality model (Simpson et al. 2012) feeds the RAINS/GAINS integrated assessment modeling tool (Amann et al. 2011) to balance emission reductions across countries in a cost-efficient manner.

With this increased use of air quality modeling in the frame of policy support, ensuring that models are accurate and robust becomes essential. It is in this context that validation protocols are currently being developed in the frame of the Forum for Air Quality Modeling (FAIRMODE) initiative ${ }^{1}$. Specific evaluation

\footnotetext{
${ }^{1}$ http://fairmode.jrc.ec.europa.eu/
} 
protocols are designed to cover different modeling needs (assessment, forecast, planning, etc.) and generally address the following tasks (Dennis et al. 2010): (1) operational (reconstruction of past/present pollution episodes and validation with measurement data), (2) probabilistic (inter-comparison of model results), (3) diagnostic (analysis of model processes), and (4) dynamic (evaluation of model responses to changes in input data such as emissions, meteorology, etc.). While methodologies and protocols have been proposed and are already well established for the operational evaluation step, an appropriate methodology for the dynamic evaluation is still lacking.

Given the lack of reference measurements for the assessment of modeled emission scenarios, model inter-comparison exercises represent one possibility to assess the uncertainty related to the model responses resulting from emission scenarios. The Citydelta (Cuvelier et al. 2007) and the Eurodelta exercises (Thunis et al. 2008) are examples of such intercomparisons at the urban and European scale, respectively. They provide confidence in a given model response by comparing it to other model responses. But these exercises remain complex to set-up, provide a snapshot at a particular instant in time, and cover only one small range of the potential model uses. Another way of assessing the ability of the models to reproduce changes in air quality due to changes in emissions is to evaluate the model abilities to reproduce past trends in air pollution (e.g., Banzhaf et al. 2015; Colette et al. 2011; Fagerli and Aas 2008; Jonson et al. 2006).

In this work, we propose a methodology to assess the quality of the model results on the basis of specific normalized indicators and of a reporting template. Obviously no "true" reference is used in this methodology but the indicators facilitate the screening of a large amount of results and the identification of possible inconsistencies. These screening indicators are divided into two categories: the first is designed to better understand the intrinsic model responses in terms of chemical reactions, meteorology, etc., while the second assess model responses in terms of their policy impacts. Both indicators are useful to check model consistency (for example to analyze differences between model versions).

We first detail the proposed methodology with a particular focus on the indicators and diagram screening template ("Indicators to support dynamic evaluation" section). We then present the indicators in the context of the EMEP/MSC-W model-based source receptor relationships ("Source-receptor relationships and potency/potential indicators" section). The modeling setup is briefly described in the "Modelling setup" section while the results of the analysis are presented in "Analysis of the EMEP source receptor relationships in terms of potencies" and "Analysis of the EMEP source receptor relationships in terms of potentials" sections. We first use the indicators to better understand the model responses while in a second step we assess their impacts on policy. Conclusions are provided in "Conclusions" Section.

\section{EMEP/MSC-W-based source receptor model}

We focus here our analysis on the EMEP/MSC-W-based source receptor model which directly feeds GAINS. GAINS is based on simplified relationships between emissions and concentrations, built on the basis of a large number of EMEP/MSC-W model simulations. Currently, more than 1000 different EMEP/MSC-W yearly simulations are performed which include precursor and country-specific emission reductions for 5 different meteorological years $(50$ countries $\times 5$ precursors $\times 5$ meteorological years, in addition to emissions from international ship traffic in 5 different areas that are considered as specific spatial entities). As an approximation, source receptor relationships are assumed to be linear and only one level of emission reduction $(15 \%)$ is selected in each country and for each precursor. A discussion of linearity issues and the reasoning behind these choices are described in Wind et al. (2004).

Every year, EMEP/MSC-W source receptor model runs are performed for the most recent year when emissions are available (normally a 2-year delay), e.g., in 2015 source receptor calculations were performed for 2013 (EMEP 2015a). The base case simulation (the simulation where no emission reductions are performed) is evaluated annually against all EMEP data (EMEP 2015b). More in-depth discussions on the performance of the EMEP/MSC-W model can be found in a number of papers (Fagerli and Aas 2008; Fagerli et al. 2007; Jonson et al. 2006; Aas et al. 2012). The EMEP/MSC-W model has also taken part in a number of inter-comparison exercises in recent years (e.g., Cuvelier et al. 2007; Fiore et al. 2009; Huijnen et al. 2010; Jonson et al. 2010; Colette et al. 2011; Langner et al. 2012).

For the source receptor matrices, it becomes challenging to perform a quality check of the results, especially because no reference (e.g., measurements) exists to benchmark the model results from emission scenarios. In the later years, the most recent EMEP/MSC-W model (corresponding to the version used for the source receptor runs) are used to recalculate trends for at least the last decade, and the results are compared to trends in observations (e.g., EMEP 2013). This procedure gives confidence in the EMEP/MSC-W model's response to emission changes. However, it is a tedious procedure that cannot be repeated every time the source receptor calculations are made. Therefore, for the source receptor matrices done every year, a less systematic approach is used: the latest SR calculations are compared to the previous SR matrices. But meteorological variability can cause differences of at least 10-20\% in air pollutant levels (Van Loon et al. 2005), and changes in the actual model version also lead to differences in terms of pollutant levels. This comparison is therefore a challenging task. A more systematic, easy-to-use approach would help the interpretation of whether the new set of SR calculations are in line with what is expected and, even more important, how potential changes/improvements in the model affect the policy relevant results. 


\section{Indicators to support dynamic evaluation}

In this section, we describe the indicators that will be used to support the analysis of the modeled scenarios. In the derivation of the indicators and follow-up analysis, concentration fields are intended as grid cell values whereas emissions are representative of an area (country in our case) over which emission are reduced in the model scenarios.

\section{Potencies}

The potency $P$ is defined as the derivative of the concentration with respect to the emissions density or in other words the rate with which the concentrations $\left(C^{i j}\right)$ in the grid cell $(i, j)$ will change as a result of an emission density change $(\varepsilon)$. Since instantaneous derivatives are not a model output, derivatives are approximated by their finite differences, i.e.,

$P_{k, \alpha}^{i j}=\left.\frac{d C^{i j}}{d \varepsilon_{k}}\right|_{\alpha} \approx \frac{\Delta C^{i j}}{\Delta \varepsilon_{k, \alpha}}=\frac{C_{k, \alpha}^{i j}-C_{B C}^{i j}}{\alpha \varepsilon_{k}}$

where $\alpha$ is the percentage emission reduction, $k$ is the reduced emission precursor, and $C_{B C}$ is the base case concentration. $P$ can be defined for any level of reduction and precursor and provides insight on the intensity or strength of the process. In the denominator, the choice of the emission density (and not absolute emissions) is made to allow comparisons among countries, or in general in between emission reduction areas which differ in size. $\varepsilon$ and $P$ are expressed in $\mathrm{t} / \mathrm{km}^{2}$ and $(\mu \mathrm{g} /$ $\left.\mathrm{m}^{3}\right) /\left(\mathrm{t} / \mathrm{km}^{2}\right)$, respectively. If the relation between concentrations and emissions is linear, $P$ becomes constant and does not depend on the percentage emission reduction. Because this indicator is independent of the amount of available emissions, we will use it in the following to analyze the model behavior, in particular the impact of atmospheric dispersion and chemistry. Note that although $P$ is independent of the overall emission quantity, it remains dependent on their spatial (both horizontal and/or vertical) or temporal distributions.

\section{Absolute potentials}

The absolute potential $\Pi$ for a reduced emission precursor " $k$ " at one grid cell location $(i, j)$ is defined as the concentration change resulting from a full (i.e., to zero level) emissions abatement over the domain of interest, i.e.,

$\Pi_{k}^{i j}=\int_{C_{B C}^{i j}}^{C_{k, 100 \%}^{i j}} d C=C_{k, 100 \%}^{i j}-C_{B C}^{i j}=\int_{\varepsilon_{B C}}^{0} P d \varepsilon_{k}$

where $C_{k, 100 \%}^{i j}$ is the concentration resulting from a reduction of $100 \%$ for the emission precursor $k$ and where the last equality results from the potency definition above. We generally approximate the total potential $(100 \%$ emission reduction) by a potential obtained with partial $(0<\alpha<100)$ emission reductions as follows:

$\Pi_{k}^{i j}=C_{k, 100 \%}^{i j}-C_{B C}^{i j} \approx \frac{C_{k, \alpha}^{i j}-C_{B C}^{i j}}{\alpha}=\Pi_{k, \alpha}^{i j}$

Because $\Pi$ (expressed in $\mu \mathrm{g} / \mathrm{m}^{3}$ ) integrates information about the process efficiency (absolute potency) but also emissions, it does not allow differentiating between these two impacts and is therefore less interesting to model developers. It is more designed to policymakers as it provides direct information on the achievable potential of reducing one specific precursor or activity sector while accounting for the emission characteristics of the geographical area.

\section{Relative potential}

The relative potential $(\pi)$ is defined as the ratio between the absolute potential $\Pi$ and the base case reference concentration, i.e.,

$\pi_{k}^{i j}=\frac{\Pi_{k}^{i j}}{C_{B C}^{i j}} \approx \frac{\Pi_{k, \alpha}^{i j}}{C_{B C}^{i j}}=\frac{C_{k, \alpha}^{i j}-C_{B C}^{i j}}{\alpha C_{B C}^{i j}}$

$\pi$ provides complementary information to $\Pi$. Table 1 provides an example of the complementary information embedded in these three indicators. In example 2, a high absolute potency can result in small relative potentials if the emission density $(\varepsilon)$ is limited and a high relative potential does not imply a high absolute potential (example 3). In the rest of the analysis, we will mostly focus on the potency and relative potential. Note also that the potency indicator introduced in Thunis et al. $(2015 \mathrm{a}, \mathrm{b})$ is equivalent to the relative potential indicator described above.
Table 1 Illustration of the complementary character of the three indicators $(P, \Pi, \pi)$ with simple arbitrary numbers (example 1 is used as reference)

\begin{tabular}{lllllll}
\hline Example & $C(\mu \mathrm{g} / \mathrm{m} 3)$ & $\Delta C(\mu \mathrm{g} / \mathrm{m} 3)$ & $\begin{array}{l}\varepsilon \\
\left(\mathrm{t} / \mathrm{km}^{2}\right)\end{array}$ & $\begin{array}{l}P \\
\left(\mu \mathrm{g} / \mathrm{m}^{3}\right) /\left(\mathrm{t} / \mathrm{km}^{2}\right)\end{array}$ & $\Pi(\mu \mathrm{g} / \mathrm{m} 3)$ & $\pi$ \\
\hline 1 & 100 & -10 & 50 & 0.2 & 10 & 0.1 \\
2 & 100 & -10 & 10 & 1 & 10 & 0.1 \\
3 & 20 & -10 & 50 & 0.2 & 10 & 0.5 \\
\hline
\end{tabular}

It is assumed that $100 \%$ of the available emissions are reduced to calculate the potencies and potentials, i.e., $\Delta \varepsilon=\varepsilon$ 


\section{Source receptor relationships and potency/potential indicators}

In the frame of integrated assessment modeling, full CTM models cannot be run online because of CPU constraints (Amann et al. 2011). A simplified model is therefore constructed to link emission changes to concentration changes. In the GAINS framework, the EMEP model is used to construct a linear relation between emissions and concentrations which takes the following form:

$C^{i j}=C_{0}^{i j}+\sum_{k=1}^{N_{k}} \sum_{c=1}^{N_{c}} \frac{\Delta C_{\alpha}^{i j}}{\Delta E_{k, c}^{\alpha}} E_{k, c}$

where $(i, j)$ denotes one grid cell within the domain, $\alpha$ is the emission reduction used to derive the source receptor relationships from the full EMEP model, and $N_{c}$ is the number of countries. Generally, this percentage reduction is assumed to be $15 \%$ regardless of the country and precursor. The background, i.e., the concentration level that would be reached if all emissions would be reduced by $100 \%$, is denoted by the subscript 0 . The double summation covers all precursors $\left(\mathrm{NO}_{\mathrm{x}}, \mathrm{VOC}, \mathrm{SO}_{2}, \mathrm{PPM}\right.$ (primary particulate matter), and $\mathrm{NH}_{3}$ for $\mathrm{PM}_{10}$ ) and all countries (50 in the EMEP/MSC-W model case). The previously defined potency and potential indicators represent the weight coefficients in these source receptor relationships. Indeed, through conversion of the emissions into emission densities, relation (5) can be directly re-expressed as:

$C^{i j}-C_{0}^{i j}=\sum_{k=1}^{N_{k}} \sum_{c=1}^{N_{C}} P_{\alpha, k, c}^{i j} \varepsilon_{k, c}$

where the potencies $P$ are obtained through systematic emission reductions $(\alpha=15 \%)$ with the full EMEP/MSC-W model and constitute an intrinsic property of the model. As mentioned above, $P$ does not depend on the amount of emissions but depends on the spatial and temporal distributions of the emissions. If linearity is assumed, no additional run is therefore required if the emission country totals were to be updated. But this would not be the case if the emission density or meteorology would change.

Relation (5) can also be expressed in terms of potentials:

$$
\begin{aligned}
C^{i j}-C_{0}^{i j} & =\sum_{k=1}^{N_{k}} \sum_{c=1}^{N_{C}} \Delta C_{\alpha}^{i j} \frac{E_{k, c}}{\Delta E_{k, c}^{\alpha}}=\sum_{k=1}^{N_{k}} \sum_{c=1}^{N_{C}} \Delta C_{\alpha}^{i j} \frac{E_{k, c}}{\alpha E_{k, c}} \\
& =\sum_{k=1}^{N_{k}} \sum_{c=1}^{N_{C}} \Pi_{\alpha, k, c}^{i j}
\end{aligned}
$$

or in terms of relative potentials, as:

$$
\frac{C^{i j}-C_{0}^{i j}}{C_{B C}^{i j}}=\sum_{k=1}^{N_{k}} \sum_{c=1}^{N_{C}} \pi_{\alpha, k, c}^{i j}
$$

by dividing both sides of the equality by the base case concentration.

It is important to stress the assumptions that are used in the derivation of these source receptor relationships: (1) all EMEP/MSC-W model potencies are calculated on the basis of a constant emission reduction level (15\%) but are assumed to remain valid for any level of emission reduction during the application of the integrated assessment scenarios. Relation (5) also assumes that interaction among precursors remain negligible. As we will see in this work, these two assumptions remain valid as long as long-term averaged quantities (e.g., yearly) are considered (Thunis et al. 2015a, b).

In this work, we will assess the validity of these assumptions for the five countries considered. Given the number of countries and precursor considered in the derivation of the EMEP/MSC-W model source receptor relationships, quality control and quality assurance are challenging tasks. This is why we propose here a template to facilitate the screening of the model results and to identify possible inconsistencies. In particular, the potency indicators will be used to build confidence in terms of chemical processes within the EMEP/MSC$\mathrm{W}$ model. Prior to the analysis, we provide a brief overview of the modeling set-up to generate the scenarios.

\section{Modeling setup}

The EMEP/MSC-W chemistry transport model (Simpson et al. 2012) has been used in this work to perform the scenario simulations over five countries in Europe: Belgium (BE), France (FR), Germany (DE), Italy (IT), and the United Kingdom (UK). Although this choice includes small, large, northern and southern EU countries to capture the European diversity, it remains arbitrary and the analysis performed here should be generalized to all EU countries for completeness.

All simulations have been performed with a spatial resolution of $50 \mathrm{~km} \times 50 \mathrm{~km}$ for the entire year 2012, using the EMEP/MSC-W model version rv4.5 and emissions for 2012 as reported to the LRTAP Convention in 2014 (EMEP 2014). Meteorology (ECMWF), boundary conditions and forest fires (FINNv1, Wiedinmyer et al. 2011) for 2012 have been used as input. In each scenario run, emissions have been reduced in one of the abovementioned country while emissions have been kept to their base case level elsewhere.

Following the methodology proposed by Thunis and Clappier (2014) and Thunis et al. (2015a, b), a series of independent simulations in which the emissions of the different precursors are reduced either independently or contemporarily is requested. For each country, the number of scenario simulations is equal to $2 \times n+2$ where $n$ is the number of emission precursors to be tested. In the case of $\mathrm{PM}_{10}$ which depends on emissions from the $\mathrm{NO}_{\mathrm{x}}, \mathrm{SO}_{2}, \mathrm{NH}_{3}, \mathrm{PPM}$, and $\mathrm{VOC}$ 
precursors, the number of simulations requested to calculate the indicators is therefore equal to 12 . These simulations consist of:

- Simulations (5) where each emission precursor is abated by a reference level. In our applications, this level is set to $15 \%$.

- Simulations (5) where each emission precursor is abated by an intermediate level (here set to $40 \%$ ). These simulations are used to calculate the indicators with a second level of reduction and test the robustness of the model responses.

- Simulations (2) in which all 5 precursor emissions are reduced contemporarily by 15 and $40 \%$, respectively. These simulations are used to assess the degree of nonlinearity in the model responses in terms of possible interactions among precursors.

For the 5 countries in this study, the total number of simulations required is $12 \times 5+$ base case, altogether 61 model simulations.

Using the results of these simulations, the different indicators $(P, \pi$, and $\Pi)$ are computed in every grid cell inside a country and plotted on different diagrams. As shown in Thunis et al. (2015a, b), the values taken by the different indicators show a large dispersion inside the same country, so that the representation of all the country points on the same diagram may affect its readability. Thunis et al. (2015a, b) therefore proposed to limit the visualization in the diagrams to a selection of points corresponding to the highest yearly averaged concentrations. This can be a percentile or a number of cells exceeding a desired threshold (for example, 10 grid cells with the highest values within the selected country). This choice leads to summarize the values of a country indicator focusing only on the worst situations (i.e., the highest concentrations). In this work, we decided to use a different selection of points with the aim of obtaining indicators that are more representative of the entire countries. This selection of points focuses on areas of interest, corresponding to the locations of the monitoring sites of the AIRBASE network (assuming that the AIRBASE measurement stations are located where decision makers need information to manage air quality problems). Finally, we modified, i.e., eliminate some grid cells from this selection to ensure a comparable balance in each country between the number of selected rural and urban stations, to avoid biasing the results in one or the other direction when comparing indicators among countries. The selection also preserves a good spatial coverage to ensure that the selected country stations are representative of the country. The AIRBASE network station classification scheme is used to differentiate urban from rural model grid cells in our analysis. The number of stations, for the year 2012, on which our analysis is based is reported in Table 2 .
Table 2 Number of stations used to calculate the indicators in each country

\begin{tabular}{lcrrrr}
\hline & BE & FR & DE & \multicolumn{1}{c}{ IT } & UK \\
\hline Rural & 5 & 88 & 83 & 70 & 26 \\
Urban & 4 & 189 & 112 & 132 & 52 \\
\hline
\end{tabular}

In Table 2, the number of rural stations available in BE has been reduced from 18 to 5 to keep a comparable urban/rural fraction of stations in all countries.

The emissions used as input for the EMEP simulations are based on EMEP (2014). Figure 1 shows the resulting emission densities across countries as well as their percentage allocation in terms of precursor.

\section{Analysis of the EMEP source receptor relationships in terms of potencies}

The diagrams used in the template are created as follows: (1) selection of (AIRBASE stations) grid cells (rural, suburban, and urban types) where to perform the analysis; (2) calculation of $P, \pi$, and $\Pi$ for each precursor and emission reduction percentages for each of these grid cells; (3) calculation of the maximum, minimum, and mean value for each of these indicators among all selected grid cell locations ; (4) extraction of the $5 \%$ highest daily averaged

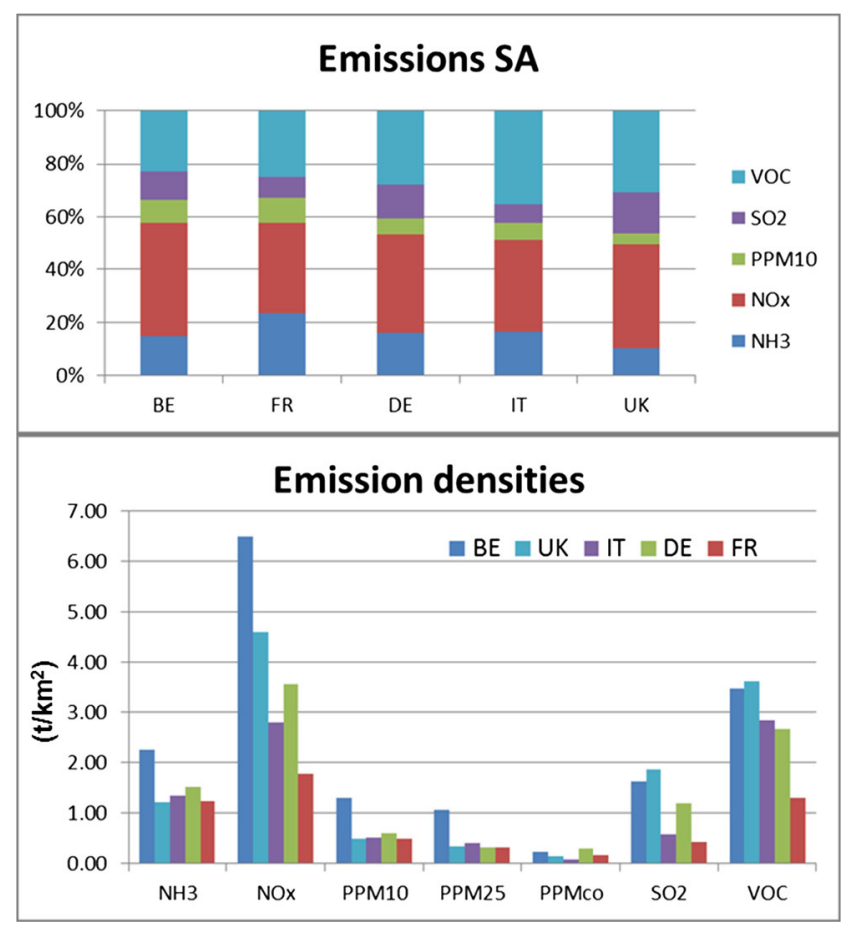

Fig. 1 The top image shows percentage allocation in terms of emission precursors per country while the bottom image shows emission densities $(\mathrm{t} / \mathrm{km} 2)$ 
concentration values within each time series and calculations of indicators as in steps 2 and 3.

Figure 2 illustrates graphically the result of this approach for $\mathrm{PM}_{10}$ over the five considered countries. The diagram is organized as follows: potencies or potentials for each precursor $\left(\mathrm{NO}_{\mathrm{x}}, \mathrm{VOC} \ldots\right)$ are expressed along a specific rectangle. Within each of these rectangles, the dark (light) blue lines links the minimum and maximum potencies obtained over the range of stations in a given country with $40 \%$ (15\%) for the long-term concentration averages while the circle represents the average (over all selected grid cells) potency. The red and orange lines follow the same principle but for the highest episodic concentrations (obtained from step 4 above).

In the case of potentials (see Fig. 6), two additional rectangles are visible. The first provides information about the potential of reducing all precursors contemporarily whereas the last rectangle provides information about non-linearity. This interaction term is obtained as the result of the difference between the sum of all individual potentials and the "all together" potential.
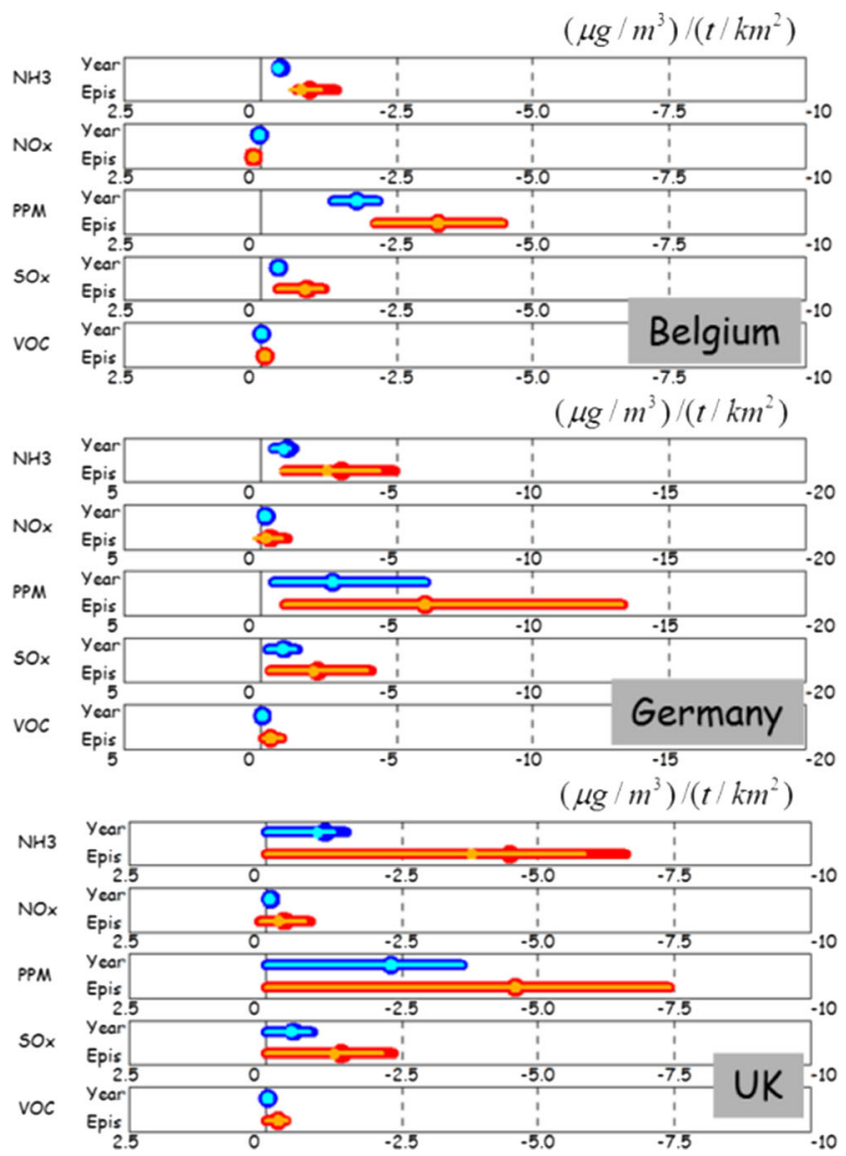

Fig. 2 Overview of the $\mathrm{PM}_{10}$ absolute potencies in the five countries. The diagram is organized as follows: potencies for each precursor $\left(\mathrm{NO}_{\mathrm{x}}\right.$, VOC...) are expressed along a specific rectangle. Within each of these rectangles, the dark (light) blue lines links the minimum and maximum potencies obtained over the range of stations in a given country with $40 \%$
Figure 2 provides details about the potencies in terms of the different precursors. The horizontal extensions of the bars provide information about the potency variability across stations (or grid cells) within a country. This variability reflects both the impact of the spatial distribution of the emissions within the country (the change of concentration will be more important where the emission density is larger within the country) but also the impact of meteorology which may differ from location to location. In the following, we will therefore use the potencies averaged over all selected grid cells (represented as circles in Fig. 2) within a country to perform the country inter-comparison, as these averages are less sensitive to meteorology or emission allocation.

In Fig. 3, the country averaged potencies for the yearly average and high percentile episodes are shown. We note the following:

- Because primary particulate matter emissions relate directly to concentrations without involving chemical reactions, they represent a good indicator of the meteorological

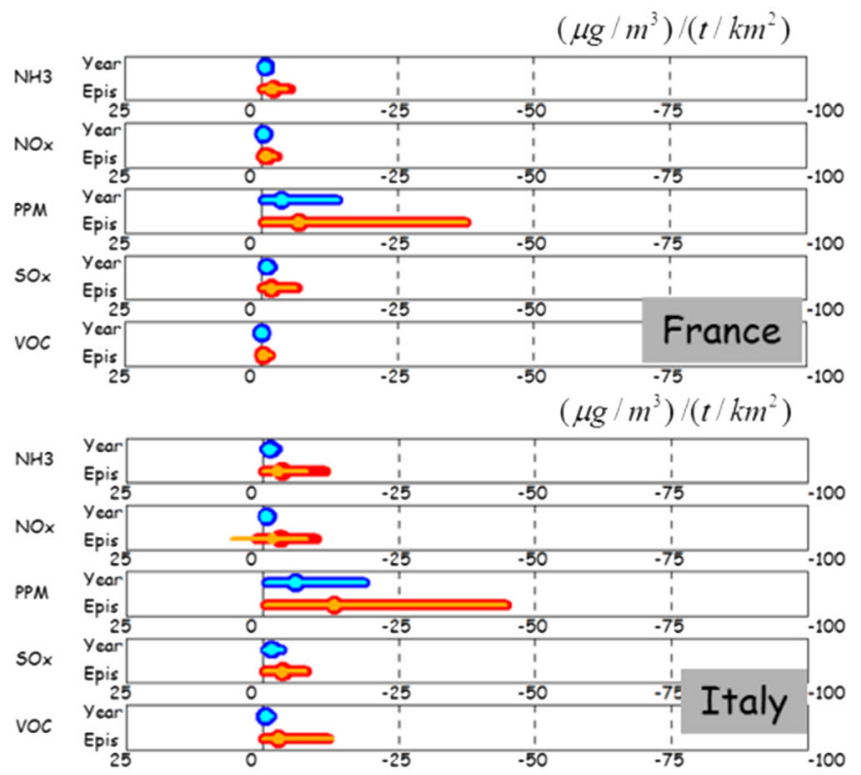

(15\%) for the long-term concentration averages while the circle represents the average (over all selected grid cells) potency. The red and orange lines follow the same principle but for the highest episodic concentrations 


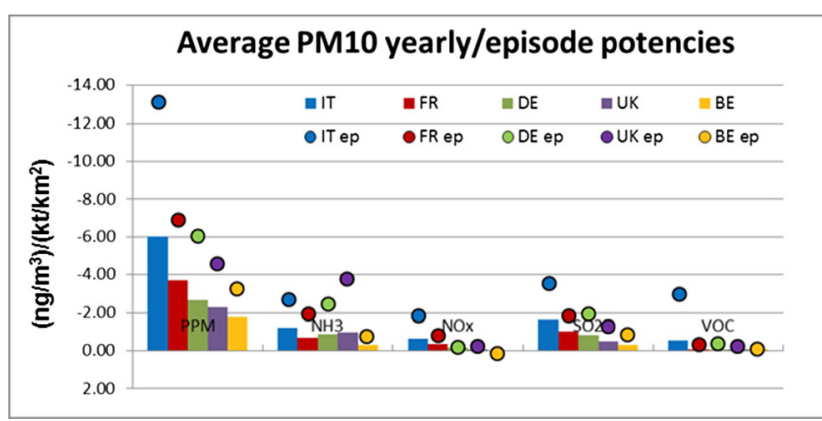

Fig. 3 Overview of the country average potencies in terms of emission precursors (bar: yearly average; circle: high percentile episode value)

impact on the efficiency of the emission to concentration conversion. $\mathrm{UK}, \mathrm{BE}$, and $\mathrm{DE}$ all show relatively similar values (around $2 \mu \mathrm{g} \times \mathrm{km}^{2} / \mathrm{t} \times \mathrm{m}^{3}$ ) while they become significantly larger in FR (around 3.7) and especially IT (6.5). Reasons for these differences among country potencies might be the frequent stagnant meteorological conditions in northern IT, reducing atmospheric dispersion (higher potencies in IT) and other meteorological factors (e.g., rain) explaining the lower potencies in BE, UK, or GE. We also note that PPM is by far the most important contributor in all countries. This is due to the fact that primary emissions are directly converted into PM concentrations, whereas all other precursors need to undergo chemical processes before leading to an increase in secondary particulate concentrations.

- The trend observed for PPM remains valid for all other precursors with larger potencies in IT, then FR followed by the other three countries. This reinforce our hypotheses that meteorology is probably here the main factor influencing the efficiency of the $\mathrm{PM}_{10}$ production

- VOC can contribute to PM "directly" via SOA formation, or indirectly through $\mathrm{O}_{3}$ formation - leading to more oxidation of, e.g., $\mathrm{SO}_{2}$ to $\mathrm{SO}_{4}{ }^{2-}$. But with the exception of IT (especially during high episodes), the potencies simulated for $\mathrm{VOC}$ remain negligible in all countries.

- UK shows proportionally larger potencies for $\mathrm{NH}_{3}$ during high-concentration episodes.

- In $\mathrm{BE}$, positive potencies are simulated for $\mathrm{NO}_{\mathrm{x}}$ (i.e., a decrease of $\mathrm{NO}_{\mathrm{x}}$ emissions leading to an increase of $\mathrm{PM}_{10}$ concentrations). In $\mathrm{BE}$, the density of the $\mathrm{NO}_{\mathrm{x}}$ emission (most of it is emitted as $\mathrm{NO}$ ) is high and their reduction tends to increase the $\mathrm{O}_{3}$ levels, which in turn favor the conversion of $\mathrm{SO}_{2}$ into $\mathrm{SO}_{4}{ }^{2-}$.

- The points mentioned for $\mathrm{PM}_{10}$ remain valid for $\mathrm{PM}_{2.5}$ (not shown). It is interesting to note that all $\mathrm{PM}_{2.5}$ potencies are larger than the $\mathrm{PM}_{10}$ ones in all countries for PPM. This is due to deposition processes which are more efficient on the coarse than on the fine particulate fraction. In terms of potencies, this can be expressed as: $P_{\alpha}^{\mathrm{PPM} 25}>P_{\alpha}^{\mathrm{PPM} 10} \Rightarrow$ $\left|\Delta C^{\mathrm{PM} 25} / \Delta E_{\alpha}^{\mathrm{PPM} 25}\right|>\left|\Delta C^{\mathrm{PMco}} / \Delta E_{\alpha}^{\mathrm{PPMco}}\right|$. Figure 4

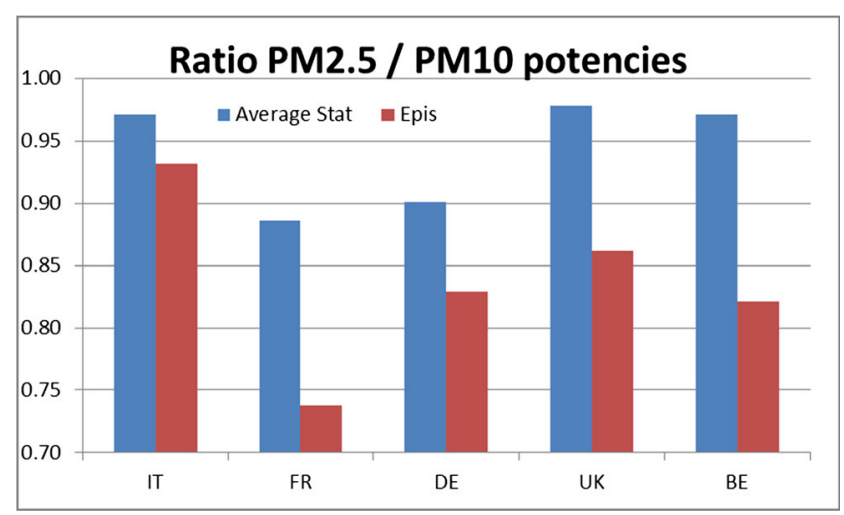

Fig. $4 \mathrm{PM}_{10} / \mathrm{PM}_{2.5}$ potency ratio for PPM emissions

shows that this process is more efficient in $\mathrm{FR}$ and $\mathrm{DE}$ (around $15 \%$ loss) and more efficient during highconcentration episodes in all countries (loss up to $25 \%$ in FR but limited to $7 \%$ in IT)

- High PM concentration episodes are generally occurring during stagnant conditions characterized by a reduced dispersion of the precursors in the atmosphere. This explains the larger potencies observed during high-concentration episodes. While the ratio between episodes and yearly average values is on the order of 2 for PPM for all countries, it reaches 5 for VOC.

As mentioned above, the spatial distribution of the emissions within a country as well as meteorology determine the extension of the bars in Fig. 2. We observe that this variability in terms of PM model response is more important for PPM emissions because local gradients in those emissions will directly impact PM concentrations (which is not the case for precursors like $\mathrm{NO}_{\mathrm{x}}$ or $\mathrm{NH}_{3}$ that will need time to impact PM through secondary aerosol formation).

An estimate of the non-linearities is obtained by comparing calculations performed with reductions of 15 and $40 \%$ (lines of different colors overlaid in Fig. 2). These non-linearities are weak with the exception of $\mathrm{NH}_{3}$ which shows some nonlinearity in all countries (especially UK). This is also the case for $\mathrm{NO}_{\mathrm{x}}$ but in IT only. Non-linearities are clearly larger for episodes than for yearly averaged values. These results are in line with those detailed in Thunis et al. $(2015 \mathrm{a}, \mathrm{b})$ where the non-linearities of the LOTOS air quality model responses were tested over three different areas, for different averaging times.

Although the indicators for $\mathrm{PM}_{10}$ and $\mathrm{PM}_{2.5}$ are very similar, they show some systematic differences. In order to facilitate the interpretation, only the indicators for the coarse PM fraction $\left(\mathrm{PM}_{\mathrm{co}}=\mathrm{PM}_{10}-\mathrm{PM}_{2.5}\right)$ are shown. We distinguish three possible behaviors, closely related to the chemical processes implemented in the EMEP model (Fig. 5). 


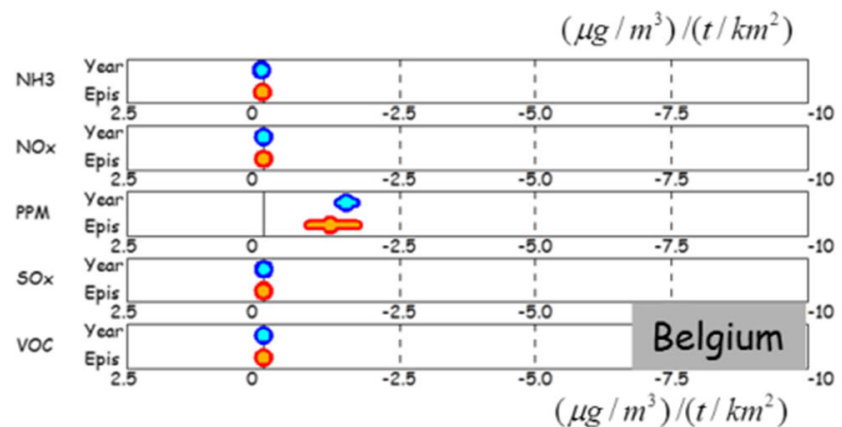

$\mathrm{NH} 3$

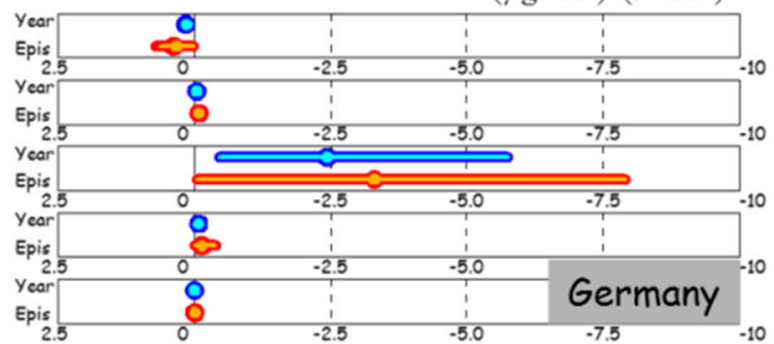

voc

$\left(\mu g / \mathrm{m}^{3}\right) /\left(t / \mathrm{km}^{2}\right)$

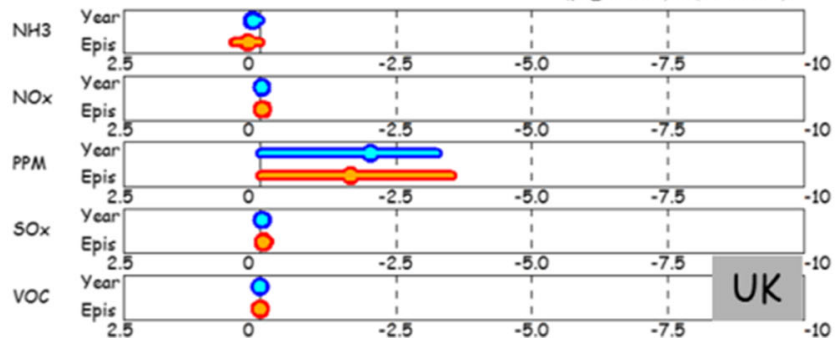

Fig. 5 Overview of the $\mathrm{PM}_{\mathrm{co}}$ absolute potencies in the five countries

- For VOC and $\mathrm{SO}_{2}$, the $\mathrm{PM}_{\text {co }}$ potencies are negligible. This is in line with the chemical processes implemented in the EMEP model and in particular with the fact that no process is supposed to generate or destroy coarse particulates from those precursor emissions.

- Increased $\mathrm{NH}_{3}$ emissions decrease the PM coarse concentrations somewhat. This process is described in Fagerli and Aas (2008) and can be summarized as follows: ammonia react with nitric acid to form ammonium nitrate in an equilibrium reaction. This process is reversible, and the equilibrium depends on, e.g., the relative humidity of deliquescence and the equilibrium constant. The nitric acid that is "left" is available for formation of coarse nitrate on soil and sea salt particles. When more ammonia is available, more ammonium nitrate is formed and less $\mathrm{HNO}_{3}$ is available for the formation of coarse nitrate-containing particles.

- $\mathrm{NO}_{\mathrm{x}}$ emissions contribute to a slight increase of PM coarse concentration through the formation of coarse nitrate on sea salt and dust described above.

As illustrated above, potencies constitute useful indicators to analyze model responses to emission scenarios. They allow

for a fast screening of the results and for a consistency check of the processes implemented in the model. They however do not provide meaningful information to the policymaker as they are expressed per emission unit. In the following section, we analyze the results in terms of the potential indicators which integrate this emission information.

\section{Analysis of the EMEP source receptor relationships in terms of potentials}

Unlike the potencies described in the previous section, potentials link potencies and emissions (see formula 3). The potentials obtained for $\mathrm{PM}_{10}$ for all stations are shown in Fig. 6. As mentioned in the "EMEP/MSC-W-based Source-Receptor Model" section, two lines are added on the diagram: the first indicates the impact of reducing all precursors contemporarily (denoted as ALL) while the last row informs about the non-linearities which could arise if precursors are reduced contemporarily in contrast to sequential reductions. We note the following:

- The "ALL" row provides information about the degree of efficiency of full emission reductions performed over the area of interest. BE shows the lowest average value with 

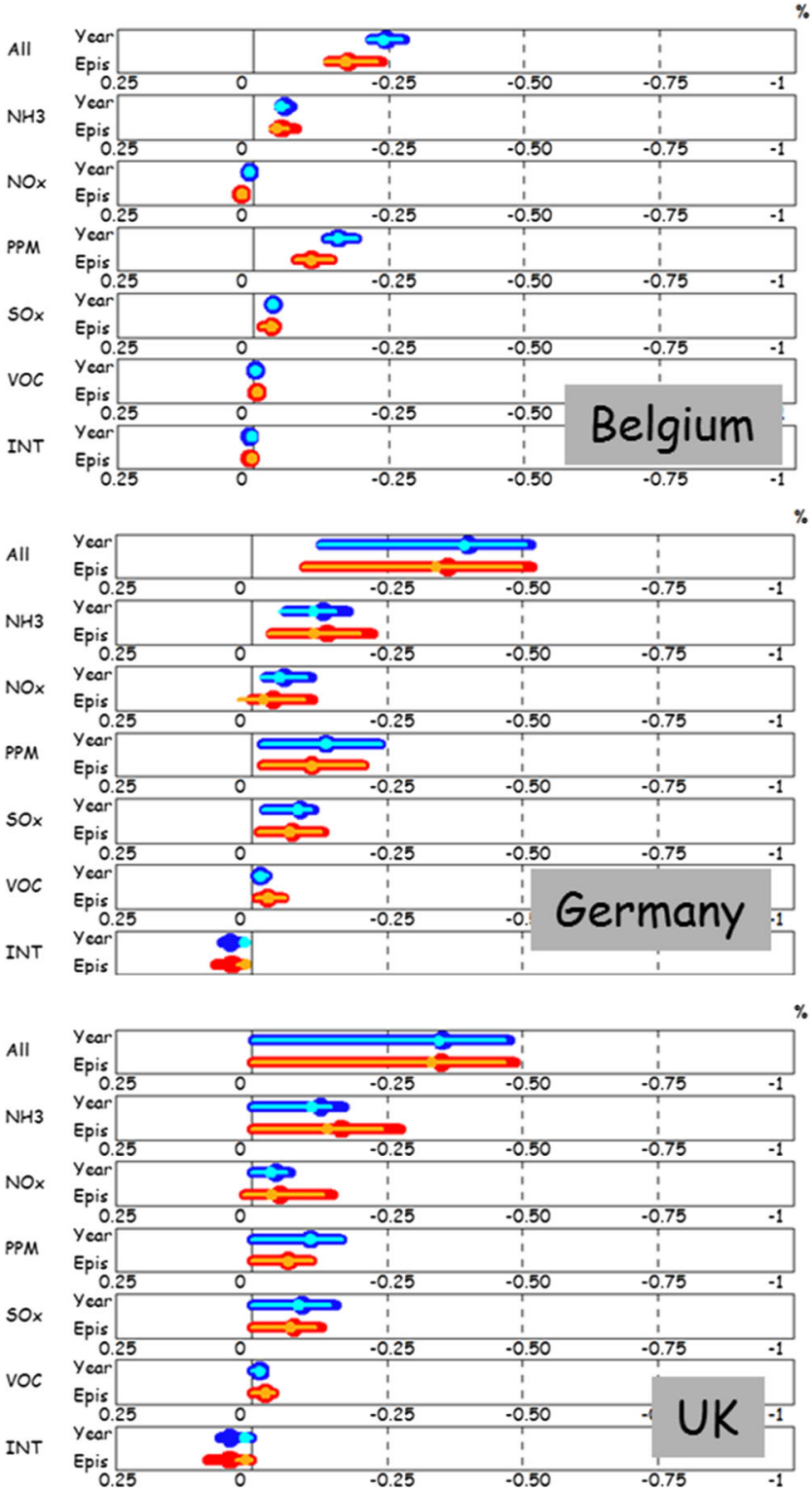

Fig. 6 Overview of the $\mathrm{PM}_{10}$ relative potentials in the five countries. For potentials, two additional rectangles are visible. The first provides information about the potential of reducing all precursors contemporarily whereas the last rectangle provides information about

$25 \%$ indicating that $75 \%$ of the $\mathrm{PM}_{10}$ levels arise from trans-boundary and natural sources in this country. FR, UK, and DE follow with 33,35 , and $40 \%$, respectively. IT shows significantly larger potential values approaching $50 \%$. Obviously, this potential depends on the size of the country (the smaller the country, the smaller the potential) but we note that countries of similar size exhibit large differences as a result of emission density, chemical regime, and/or meteorological conditions. A good example is $\mathrm{BE}$ where the small dimension of the country is compensated by high emission densities leading to almost comparable potentials. Note also that all these numbers
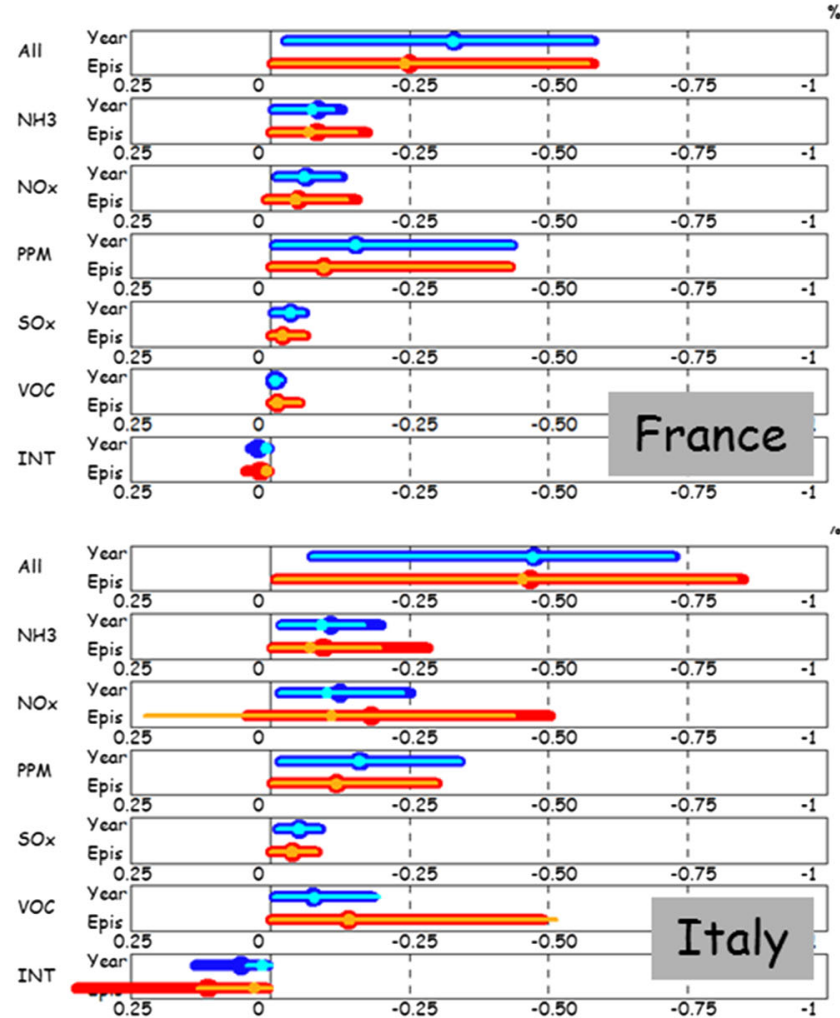

non-linearity. This interaction term is obtained as the result of the difference between the sum of all individual potentials and the "all together" potential

are representative of country averages and individual station values can be much larger (or smaller).

- While potencies were seen to be larger for PPM in terms of precursors in all countries, it remains the case in most countries for potentials but the importance of other precursors tends to grow. This is particularly the case for $\mathrm{NH}_{3}$ but the other three (VOC, $\mathrm{NO}_{\mathrm{x}}$, and $\mathrm{SO}_{2}$ ) also reach significant values in terms of potentials.

The importance of the agricultural emissions on PM formation is also discussed, e.g., in Bessagnet et al. (2014) and 
Thunis et al. (2008). The high potentials for $\mathrm{NH}_{3}, \mathrm{NO}_{\mathrm{x}}$, VOC, and $\mathrm{SO}_{2}$ are caused by the high abundance of emissions (see Fig. 2) which compensates the relatively weak potency described in the previous section. This is visible especially for $\mathrm{NO}_{\mathrm{x}}$ and VOC which show weak potencies but relatively large potentials due to the large fraction of emissions available for these two precursors.

- The comparison of the precursor potential in terms of percentage contribution between episodes and yearly averages highlights interesting differences across countries. In UK, the importance of $\mathrm{NH}_{3}$ grows during episodes as compared to yearly averages whereas $\mathrm{NO}_{\mathrm{x}}$ plays this role in BE and VOC in IT.

- Similarly to the analysis of the potencies, non-linearities for potentials appear for $\mathrm{NH}_{3}$ in all countries and for $\mathrm{NO}_{\mathrm{x}}$ in IT but they tend to remain small for yearly averaged values. This is not the case for episodes where these nonlinearities become important and cannot be neglected. The non-linear interaction (difference between the impact of reducing each precursor sequentially and contemporarily) also remains weak for yearly averages but tend to be larger for episodes, especially in IT.

- In all countries, the stations located in highly urbanized or industrialized areas logically show the highest potentials (the Paris area in FR, the Po Valley cities in IT, the Ruhr industrialized area in DE), whereas the lowest values belong to the rural areas.

\section{Conclusions}

In this work, the methodology based on the calculation of potencies proposed by Thunis and Clappier (2014) is further developed and used to screen modeled emission reduction scenarios performed with the EMEP/MSC-W air quality model. Focus is on $\mathrm{PM}_{10}$ and its related emission precursors $\left(\mathrm{NH}_{3}\right.$, $\mathrm{NO}_{\mathrm{x}}, \mathrm{VOC}, \mathrm{PPM}$, and $\mathrm{SO}_{2}$ ). Specific indicators have been proposed to look at the results in terms of model processes (potencies) as well as in terms of their impacts on policy (potentials). A specific template to screen the results has also been developed and applied in this study.

This methodology proved to be useful, especially in the frame of source receptor modeling where a large number of full CTM simulations are generally requested to identify the coefficients of the source receptor relationships. Because no "true reference" exists in the case of model scenarios (no observations), quality assurance is a difficult task. The methodology proposed in this work must be seen as one step to facilitate this task.

The model results obtained in $5 \mathrm{EU}$ countries for 5 precursors and 2 levels of emission reductions (15 and $40 \%$ ) have been analyzed both in terms of potencies and potentials. Based on a set of 12 emission reduction scenario simulations per country (in addition to a base case simulation), potency and potential indicators were calculated for the following purposes:

- Build confidence in the processes implemented in the model to generate/destroy particulate matter

- Identify the potential of country emission abatement action vs. trans-boundary transport

- Assess the relative importance of the various precursors emission which have a potential impact on $\mathrm{PM}_{10}$ concentrations

- Estimate the robustness of the model responses (i.e., how much would my response change if another reduction level is selected?)

- Estimate the degree of non-linearity among precursors (i.e., how would my response change if I reduce all precursors contemporarily rather than sequentially?)

This methodology revealed to be very useful to compare the responses across countries and precursors in a uniform way. The results confirmed our knowledge in terms of processes implemented in the EMEP model. The validity of the linear assumption made during the derivation of the EMEPbased source receptor relationships has also been assessed. Generally, this linear assumption is valid but the indicators showed some minor non-linearities which would lead to some possible underestimation with respect to $\mathrm{NH}_{3}$ in all countries (due to non-linearities) but also with respect to $\mathrm{NO}_{\mathrm{x}}$ in IT. The linear assumption remains therefore generally valid for yearly averaged $\mathrm{PM}_{10}$ concentrations, while for episode studies they should be accounted for.

As mentioned, no true reference can be used to assess the quality of the model results but it is important to consider this screening as a benchmark to which other models can be compared later on at the national scale. Updated versions of the EMEP/MSC-W model could also be compared to this reference to ensure consistent deliveries in terms of policy impacts. Because only five countries were considered, a full assessment could not be performed but it is the intention of the authors to extend this work to all countries to constitute an exhaustive benchmark.

Acknowledgments The EMEP/MSC-W source receptor calculations made available for this work have been funded by the Co-operative Programme for Monitoring and Evaluation of the Long-range Transmission of Air pollutants in Europe (EMEP) under UNECE.

This work has also received support from the Research Council of Norway (Programme for Supercomputing) through CPU time granted at the super computers at NTNU in Trondheim, the University of Tromsø, and the University of Bergen. 


\section{References}

Aas W, Tsyro S, Bieber E, Bergstrom R, Ceburnis D, Ellermann T, Fagerli H, Frolich M, Gehrig R, Makkonen U, Nemitz E, Otjes R, Perez N, Perrino C, Prevot A, Putaud JP, Simpson D, Spindler G, Vana M, Yttri KE (2012) Lessons learnt from the first EMEP intensive measurement periods. Atmos Chem Phys Discuss 12:3731-3780

Amann M, Bertok I, Borken-Kleefeld J, Cofala J, Heyes C, HöglundIsaksson L, Klimont Z, Nguyen B, Posch M, Rafaj P, Sandler R, Schöpp W, Wagner F, Winiwarter W (2011) Cost-effective control of air quality and greenhouse gases in Europe: modelling and policy applications. Environ Model Softw 26:1489-1501

AQD (2008) Directive 2008/50/EC of the European Parliament and of the Council of 21 May 2008 on ambient air quality and cleaner air for Europe ( No. 152), Official Journal

Banzhaf S, Schaap M, Kranenburg R, Manders AM, Segers AJ, Visschedijk AJ, Denier van der Gon HA, Kuenen JJ, van Meijgaard E, van Ulft LH, Cofala J, Builtjes PJ (2015) Dynamic model evaluation for secondary inorganic aerosol and its precursors over Europe between 1990 and 2009. Geosci Model Dev 8(4): $1047-1070$

Bessagnet B, Beauchamp M, Guerreiro C, de Leeuw F, Tsyro S, Colette A, Meleux F, Rouil L, Ruyssenaars P, Sauter F, Velders G, Foltescu V, van Aardenne J (2014) Can further mitigation of ammonia emissions reduce exceedances of particulate matter air quality standards? Environ Sci Pol 44:143-163

Colette A, Granier C, Hodnebrog Ø, Jakobs MA, Nyiri A, Bessagnet B, D'Angiola A, D'Isidoro M, Gauss M, Meleux F, Memmesheimer M, Mieville A, Rouil L, Russo F, Solberg S, Stordal F, Tampieri F (2011) Air quality trends in Europe over the past decade: a first multi-model assessment. Atmos Chem Phys 11(22):11657-11678

Cuvelier C, Thunis P, Vautard R, Amann M, Bessagnet B, Bedogni M, Berkowicz R, Brandt J, Brocheton F, Builtjes P, Carnavale C, Coppalle A, Denby B, Douros J, Graf A, Hellmuth O, Hodzic A, Honore C, Jonson J, Kerschbaumer A, de Leeuw F, Minguzzi E, Moussiopoulos N, Pertot C, Peuch VH, Pirovano G, Rouil L, Sauter F, Schaap M, Stern R, Tarrason L, Vignati E, Volta M, White L, Wind P, Zuber A (2007) CityDelta: a model intercomparison study to explore the impact of emission reductions in European cities in 2010. Atmos Environ 41:189-207

Dennis R, Fox T, Fuentes M, Gilliland A, Hanna S, Hogrefe C, Irwin J, Rao ST, Scheffe R, Schere K, Steyn D, Venkatram A (2010) A framework for evaluating regional scale numerical photochemical modeling systems. Environ Fluid Mech 10:471-489

EEA (2011) The application of models under the European Union's Air Quality Directive: a technical reference guide. Technical report No 10/2011

EMEP (2013) Transboundary particulate matter, photo-oxidants, acidifying and eutrophying components, EMEP status report 1/2013

EMEP (2014) Transboundary particulate matter, photo-oxidants, acidifying and eutrophying components, EMEP status report 1/2014
EMEP (2015a) Transboundary particulate matter, photo-oxidants, acidifying and eutrophying components, EMEP status report 1/2015

EMEP (2015b) Transboundary particulate matter, photo-oxidants, acidifying and eutrophying components, Supplementary material, EMEP status report $1 / 2015$

Fagerli H, Aas W (2008) Trends of nitrogen in air and precipitation: model results and observations at EMEP sites in Europe, 19802003. Environ Pollut 154(3):448-461

Fagerli H, Legrand M, Preunkert S, Vestreng V, Simpson D, Cerquira M (2007) Modeling historical long-term trends of sulfate, ammonium and elemental carbon over Europe: a comparison with ice core records in the Alps. J Geophys Res. doi:10.1029/2006JD008044

Fiore A, Dentener F, Wild O, Cuvelier C et al (2009) Multi-model estimates of intercontinental source-receptor relationships for ozone pollution. J Geophys Res. doi:10.1029/2008JD010816

Huijnen V, Eskes HJ, Poupkou A, Elbern H et al (2010) Comparison of OMI NO2 tropospheric columns with an ensemble of global and European regional air quality models. Atmos Chem Phys 10: 3273-3296

Jonson JE, Simpson D, Fagerli H, Solberg S (2006) Can we explain the trends in European ozone levels? Atmos Chem Phys 6:51-66

Jonson JE, Stohl A, Am F et al (2010) A multi-model analysis of vertical ozone profiles. Atmos Chem Phys 10:5759-5783

Langner J, Engardt M, Baklanov A, Christensen JH, Gauss M, Geels C, Hedegaard GB, Nuterman R, Simpson D, Soares J, Sofiev M, Wind P, Zakey A (2012) A multi-model study of impacts of climate change on surface ozone in Europe. Atmos Chem Phys 12:10423-10440

Simpson D, Benedictow A, Berge H, Bergström R et al (2012) The EMEP MSC-W chemical transport model-technical description. Atmos Chem Phys 12(16):7825-7865

Thunis P, Clappier A (2014) Indicators to support the dynamic evaluation of air quality models. Atmos Environ 98:402-409

Thunis P, Cuvelier C, Roberts P et al (2008) EuroDelta-II, evaluation of a sectorial approach to integrated assessment modelling including the Mediterranean Sea. JRC Scientific and Technical Reports -EUR 23444 EN

Thunis P, Clappier A, Pisoni E, Degraeuwe B (2015a) Quantification of non-linearities as a function of time averaging in regional air quality modeling applications. Atmos Environ 103:263-275

Thunis P, Pisoni E, Degraeuwe B, Kranenburg R, Schaap M, Clappier A (2015b) Dynamic evaluation of air quality models over European regions. Atmos Environ 111:185-194

Van loon M, Wind P, Tarrason L (2005) Meteorological variability in source allocation. In: Transboundary contributions across Europe, EMEP Status report 1/2005, chapter 6

Wiedinmyer C, Akagi SK, Yokelson RJ, Emmons LK, Al-Saadi JA, Orlando JJ, Soja J (2011) The Fire INventory from NCAR (FINN): a high resolution global model to estimate the emissions from open burning. Geosci Model Dev 4:625-641

Wind P, Simpson D, Tarrason L (2004) Source-receptor calculations. In: EMEP Status report 1/2004, chapter 4 